\title{
Astragalin Inhibits Nuclear Factor-kB Signaling in Human Colonic Epithelial Cells and Attenuates Experimental Colitis in Mice
}

\author{
Yoo Min Han ${ }^{1,2}$, Jaemoon Koh³ , Jee Hyun Kim4, Jooyoung Lee ${ }^{1,2}$, Jong Pil Im¹, and Joo Sung Kim,2 \\ ${ }^{1}$ Department of Internal Medicine and Healthcare Research Institute, Seoul National University Hospital Healthcare System Gangnam \\ Center, ${ }^{2}$ Department of Internal Medicine and Liver Research Institute and ${ }^{3}$ Department of Pathology, Seoul National University \\ Hospital, Seoul National University College of Medicine, Seoul, and ${ }^{4}$ Department of Internal Medicine, CHA Bundang Medical Center, \\ CHA University School of Medicine, Seongnam, Korea
}

\section{Article Info}

Received August 1, 2019

Revised December 23, 2019

Accepted January 7, 2020

Published online May 13, 2020

Corresponding Author

Joo Sung Kim

ORCID https://orcid.org/0000-0001-6835-4735

E-mail Jooskim@snuh.ac.kr
Background/Aims: Astragalin (kaempferol-3-O- $\beta$-D-glucoside) is a flavonoid isolated from the leaves of persimmon or Rosa agrestis. Astragalin exhibits various anti-inflammatory properties; however, little is known about its therapeutic potential for inflammatory bowel disease (IBD). This study aims to investigate the anti-inflammatory effect of astragalin via blockade of the nuclear factor $\mathrm{KB}(\mathrm{NF}-\mathrm{KB})$ signaling pathway in human colonic epithelial cells and a murine colitis model. Methods: HCT-116 and HT-29 human colonic epithelial cells were pretreated with astragalin and stimulated with tumor necrosis factor- $\alpha$ (TNF- $\alpha$ ). Cell viability was assessed by the MTS assay. Real-time reverse transcription polymerase chain reaction was used to analyze the messenger RNA expression of the inflammatory cytokines interleukin (IL)-6 and IL-8. The effect of astragalin on the NF-KB pathway was evaluated by Western blot analysis of inhibitor of NF-kB alpha (IKBa) phosphorylation/degradation and by electrophoretic mobility shift assay. Dextran sulfate sodium (DSS)-induced acute murine colitis model was used for in vivo experiments.

Results: Astragalin strongly suppressed the expression of proinflammatory cytokines in human colonic epithelial cells in a dose-dependent manner. Western blot analysis showed that astragalin inhibited IKBa phosphorylation/degradation. Additionally, astragalin reduced the DNA binding activity of NF-KB. Astragalin alleviated colon shortening and improved the pathologic scores in DSSinduced acute murine colitis model. Furthermore, astragalin reduced the level of phosphorylated IKB $\alpha$ and decreased the production of the inflammatory cytokines IL-6, IL-8, and TNF- $\alpha$ in the DSS-treated colon mucosa.

Conclusions: Astragalin exerted an anti-inflammatory effect through NF-KB pathway inhibition and attenuated murine colitis. Astragalin is thus a potential therapeutic agent for IBD. (Gut Liver $2021 ; 15: 100-108)$

Key Words: Astragalin; Human colonic epithelial cells; NF-kappa B; Colitis; Inflammatory bowel disease

\section{INTRODUCTION}

Inflammatory bowel disease (IBD), which is represented by ulcerative colitis and Crohn's disease, is a chronic inflammatory disorder involving gastrointestinal tract. Although the incidences of ulcerative colitis and Crohn's disease have increased significantly in Asia in the past two decades, they are still the highest in the West. ${ }^{1}$ Although the pathogenesis of IBD is not clear, multiple factors such as genetic predisposition, host-microbial interaction, and immunologic imbalance are thought to contribute. ${ }^{2,3}$ The colonic microenvironment plays an important role, which includes inflammatory cells like neutrophils, monocytes, and $\mathrm{T}$ cells as well as cytokines and chemokines secreted by these cells. ${ }^{4}$

Nuclear factor- $\kappa \mathrm{B}(\mathrm{NF}-\kappa \mathrm{B})$ signaling pathway is one of the dominant signaling pathways involved in pathogenesis of IBD. ${ }^{5,6}$ There has been a report that NF- $\kappa$ B overexpres- 
sion and activation were observed in macrophages and intestinal epithelial cells obtained from inflamed intestinal tissues of IBD patients. ${ }^{7}$ Since NF- $\kappa$ B pathway brought about a proinflammatory cascade and promoted the production of various proinflammatory cytokines, modulation of this inflammatory pathway is important in these patients.

Astragalin (kaempferol-3-O- $\beta$-D-glucoside), which is a natural flavonoid extracted from the leaves of Rosa agrestis or persimmon, has been used as a traditional Chinese prescription as it has shown anti-inflammatory and antioxidant effect. There were several evidences that astragalin has an anti-inflammatory effect by blockage of NF- $\kappa B$. ${ }^{8}$ Previous study reported that astragalin suppressed the production of nitric oxide, prostaglandin $\mathrm{E}_{2}$, and interleukin (IL)-6 in lipopolysaccharide (LPS)-activated RAW 264.7 cells. ${ }^{9}$ It also have been reported that astragalin had inhibitory effect of tumor necrosis factor- $\alpha$ (TNF- $\alpha$ ) production in RAW 264.7 cells. ${ }^{10}$ By inactivation of NF- $\kappa$ B pathway, astragalin showed decreased production of TNF- $\alpha$, IL- 6 , IL-1 $\beta$ in murine model of LPS-induced acute lung injury. ${ }^{11}$ However, little is known on therapeutic potential of astragalin for IBD. This study aimed to investigate the antiinflammatory effect of astragalin by blockade of NF- $\kappa \mathrm{B}$ signaling pathway in human colonic epithelial cells and murine colitis model.

\section{MATERIALS AND METHODS}

\section{Cells and materials}

The HCT-116 and HT-29 cells were purchased by the Korean Cell Line Bank (Seoul, Korea). Astragalin and LPS (Escherichia coli 0127:B8) were obtained from SigmaAldrich Chemical Co. (St. Louis, MO, USA). MTS kit was supplied by Promega (CellTiter $96^{\circledR}$ Aqueous, Madison,

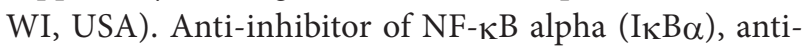
phosphorylated $\mathrm{I}_{\kappa} B \alpha$ antibodies were purchased from Cell Signaling (Danvers, MA, USA) and anti- $\beta$-actin and antiNF- $\kappa$ B p50 antibodies were supplied by Santa Cruz Biotechnology (Santa Cruz, CA, USA). LightShift Chemiluminescent EMSA Kit from Thermo Scientific Inc. (Rockford, IL, USA) was used for electrophoretic mobility shift assays (EMSAs).

\section{Mice}

The ethical approval of this study was granted by the Institutional Animal Care and Use Committee of Seoul National University, Seoul, Korea (IACUC number: SNU170012). All procedures involving animals were in accordance with the Guide for the Care and Use of Laboratory
Animals (NIH publication no. 80-23, revised in 1978).

Six-week-old C57BL/6 wild-type mice were purchased from Koatech (Pyeongtaek, Korea) and breed in specific pathogen free conditions. A standard liberal diet was provided and mice were grown under 12/12-hour day/night cycle till they became desired age ( 7 to 9 weeks) and body weight (19 to $22 \mathrm{~g}$ ). Ventilated cages with $50 \% \pm 5 \%$ relative humidity and $24^{\circ} \mathrm{C} \pm 2^{\circ} \mathrm{C}$ temperature under specific pathogen free conditions were maintained for mice.

\section{Cell viability}

The cell viability was assessed by MTS assay. The HCT116 and HT-29 cells were planted in 96-well plates and manipulated with various concentrations of astragalin for 24 hours. Cells were incubated with MTS for 4 hours and then $150 \mu \mathrm{L}$ of dimethyl sulfoxide (DMSO) was applied to solubilize formazan. Cell viability was measured as relative absorbance at $570 \mathrm{~nm}$ compared to control.

\section{Real-time reverse transcription polymerase chain reaction}

The expression of messenger RNA (mRNA) for IL-6, IL-8 and TNF- $\alpha$ were analyzed by using real-time reverse transcription polymerase chain reaction (RT-PCR). The HCT-116 and HT-29 cells were preconditioned with and without astragalin for 24 hours and stimulated with 10 $\mathrm{ng} / \mathrm{mL}$ of TNF- $\alpha$ for 30 minutes. Intracellular RNAs were extracted from HCT-116 and HT-29 cells using TRIzol (Gibco/BRL, Gaithersburg, MD, USA). The mRNAs of IL6 , IL-8, TNF- $\alpha$ and $\beta$-actin were amplified by RT-PCR. Primers were constructed using Primer Express version 2.0 (Applied Biosystems, Foster City, CA, USA). The fold changes of IL-6, IL-8, and TNF- $\alpha$ mRNA expression were compared to that of $\beta$-actin.

\section{Western blot}

Cells were pretreated with and without astragalin, stimulated by $10 \mathrm{ng} / \mathrm{mL}$ of TNF- $\alpha$ for 30 minutes. Change of phosphorylated $\mathrm{I}_{\kappa} \mathrm{B} \alpha$ and $\mathrm{I}_{\kappa} \mathrm{B} \alpha$ after treatment by TNF- $\alpha$ were evaluated by using anti-IКB $\alpha$, anti-phosphorylated $\mathrm{I}_{\kappa} \mathrm{B} \alpha$ and anti- $\beta$-actin antibodies. ${ }^{12}$ Image Gauge version 3.12 (Fuji Photo Film, Tokyo, Japan) and Luminescent Image analyzer LAS 1000-plus (Fuji Photo Film) were used to analyze the density of protein bands. ${ }^{13}$ The phosphorylation and degradation of IкB $\alpha$ were measured by comparing density of the phosphorylated $I_{\kappa} B \alpha$ band to that of the I $B \alpha$ band.

\section{Electrophoretic mobility shift assay}

Changes in the DNA binding activity of NF- $\mathrm{KB}$ were detected by using EMSA analysis. ${ }^{14}$ Pretreated cells with 
and without astragalin were stimulated with TNF- $\alpha$ (10 $\mathrm{ng} / \mathrm{mL}$ ) for 1 hour. A biotin labeled DNA oligonucleotide probe for NF- $\kappa \mathrm{B}$ consensus site was added to nuclear extracts to measure DNA binding activity of NF- $\mathrm{kB}$. Anti$\mathrm{NF}-\kappa \mathrm{B}$ p50 antibodies were used for a supershift assay. Bounded and unbounded DNA samples were loaded on to a $5 \%$ polyacrylamide gel and electrophoresis was done. We transferred separated DNAs to a nylon membrane, and detected target DNA labeled with biotin using chemiluminescence.

\section{DSS-induced acute murine colitis model}

Seven-week-old wild-type C57BL/6 mice, approximately $20 \mathrm{~g}$ in weight, were used for the acute murine colitis model. Dextran sulfate sodium (DSS) of $4 \%$ was used to induce colitis. After body weight check, 24 mice were randomly allocated into four groups (control, vehicle, astragalin $2 \mathrm{mg} / \mathrm{kg}$, and astragalin $5 \mathrm{mg} / \mathrm{kg}$ ). Filtered water was supplied for 7 days for the control group. The vehicle group administered DMSO for 7 days. Astragalin was dissolved in the same volume of DMSO and received by oral gavage once daily over 7 days in astragalin group. The vehicle group and astragalin group received drinking water mixed with 4\% DSS during 5 days after prior administration of DMSO or astragalin for 2 days. ${ }^{12,14,15}$ We checked the body weight daily and sacrificed all mice on day 8 . After sacrifice, entire colon was extracted and colon length was measured. The colon was dissected into two pieces representative for proximal and distal colon and incised longitudinally.

Hematoxylin and eosin staining was done for formalinfixed paraffin-embedded slides. The severity of inflammation was scored by a pathologist who was blinded to the details of study. We measured the extent of crypt damage and inflammation by a score (score from 1 to 4 ) for the in- volved area and calculated the sum as a histologic score. ${ }^{16}$

$I_{\kappa} B \alpha$ phosphorylation was evaluated using immunohistochemical staining to figure out the protective effect of astragalin in the colon. Intensity of immunoreactivity for phospho-IKB $\alpha$ immunohistochemistry was evaluated according to a 0 to $4+$ scale for each slide. The scoring system for overall intensity of the staining reaction was measured accordingly: 0 revealed no immunoreactivity, no positive cells; $1+$ revealed weak immunoreactivity, less than $10 \%$ cells with positivity; $2+$ revealed mild immunoreactivity, $10 \%-30 \%$ cells with positivity; $3+$ revealed moderate immunoreactivity, $31 \%-60 \%$ cells with positivity; and $4+$ revealed strong immunoreactivity, $61 \%-100 \%$ cells with positivity. The total percentage of cells with positivity $(0$ through $4+$ ) was documented for each case. ${ }^{15}$

The expression of mRNA for IL-6, IL- 8 and TNF- $\alpha$ in mice colon tissue were analyzed using real-time RTPCR. Total RNAs were extracted from tissue samples. The mRNA of IL-6, IL-8, TNF- $\alpha$ and $\beta$-actin were amplified by real-time RT-PCR. Primers were constructed by Primer Express version 2.0 (Applied Biosystems). The fold changes of IL-6, IL-8, and TNF- $\alpha$ mRNA expression were compared to that of $\beta$-actin.

\section{Statistical analysis}

Data are presented as mean \pm standard deviation. GraphPad Prism software version 5.0 (GraphPad, La Jolla, CA, USA) was used for statistical analysis. For the analysis of continuous variables, an independent t-test or one-way analysis of variance was used. Repeated measured analysis of variance was performed to compare body weight changes among the groups. Pairwise comparison was conducted using Tukey's post hoc analysis. p-values $<0.05$ were considered statistically significant.

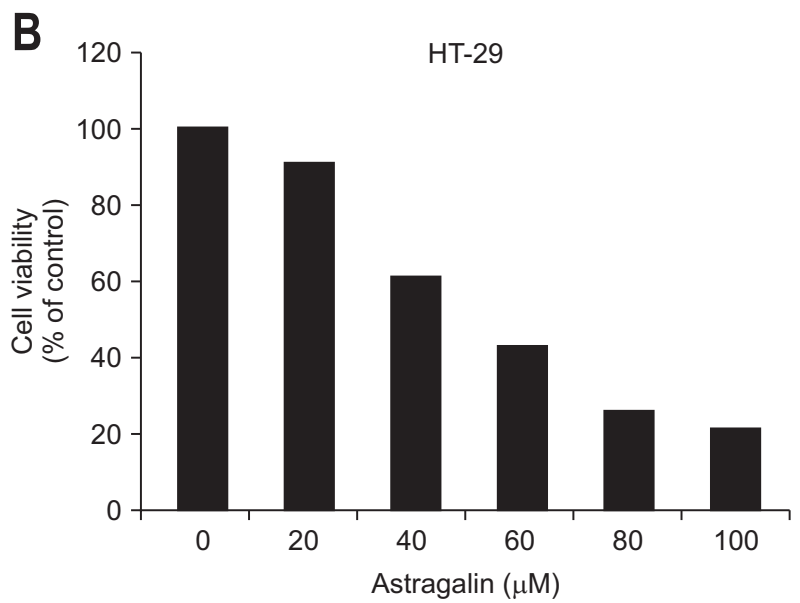

Fig. 1. Effect of astragalin on the growth of colonic epithelial cells. (A) HCT-116 and (B) HT-29 cells were treated with astragalin at different concentrations $(0,20,40,60,80$, and $100 \mu \mathrm{M})$ for 24 hours, and cell viability was evaluated by an MTS assay. 


\section{RESULTS}

\section{Astragalin inhibits colon cell proliferation}

MTS assay was performed to evaluate the effects of astragalin on colonic epithelial cell proliferation. The growth of HCT-116 and HT-29 cells was significantly prohibited dose-dependently (Fig. 1).
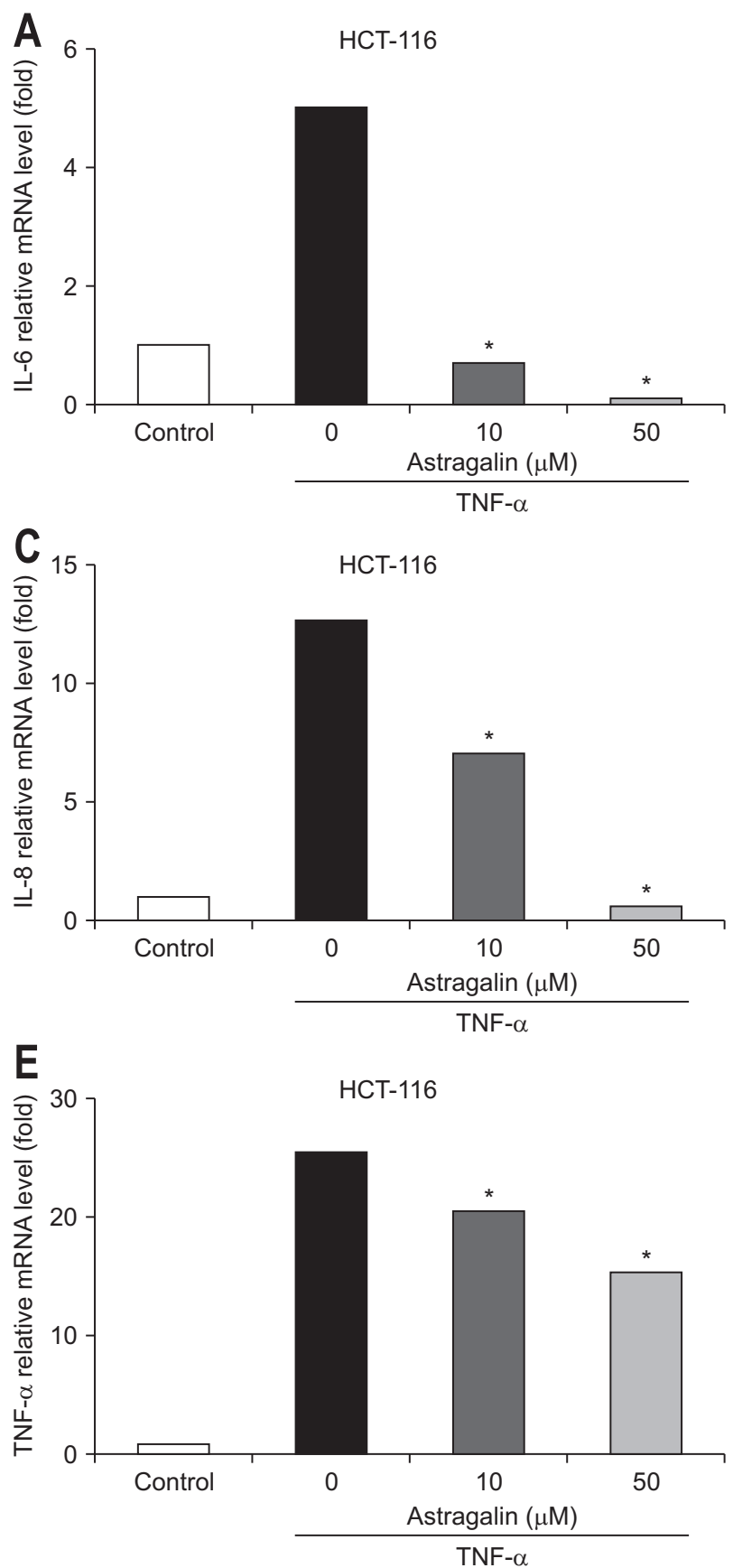

\section{Astragalin inhibits the production of inflammatory cytokines in TNF- $\alpha$-stimulated HCT-116 and HT-29 cells}

To investigate anti-inflammatory effect of astragalin, mRNA expressions for IL-6, IL- 8 , and TNF- $\alpha$ were analyzed using RT-PCR. Preconditioning with astragalin markedly reduced TNF- $\alpha$-induced IL- 6 mRNA expression
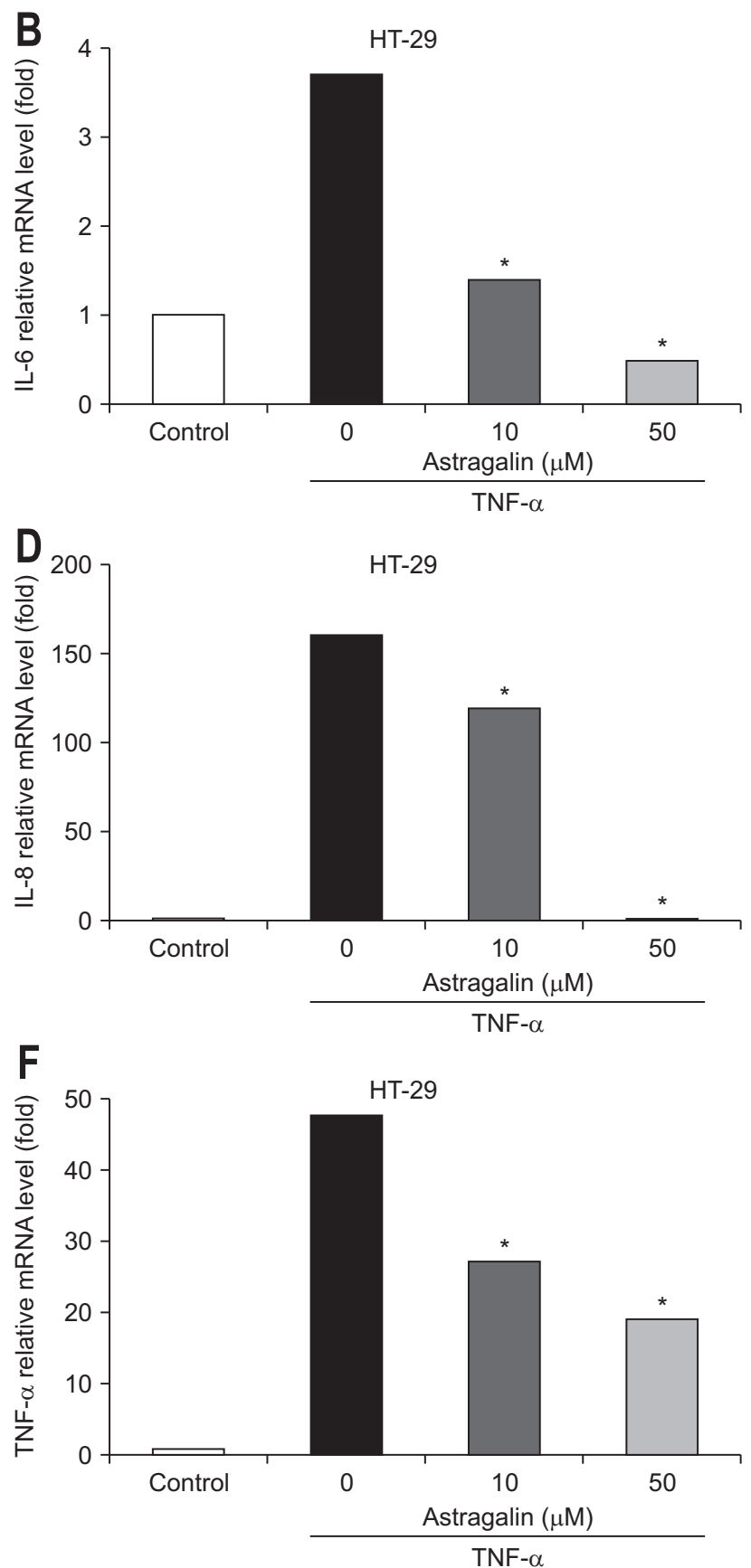

Fig. 2. Effect of astragalin on the messenger RNA (mRNA) expression of inflammatory cytokines in colonic epithelial cells. HCT-116 and HT-29 cells were pretreated with astragalin at different concentrations $(0,10$, and $50 \mu \mathrm{M})$ and stimulated with $10 \mathrm{ng} / \mathrm{mL}$ tumor necrosis factor a (TNF-a) for 30 minutes. Reverse transcription polymerase chain reaction was performed to detect the mRNA expression levels of interleukin-6 (IL-6) and IL-8. (A) IL-6 in HCT-116 and (B) HT-29 cells. (C) IL-8 in HCT-116 and (D) HT-29 cells. (E) TNF-a in HCT-116 and (F) HT-29 cells. *p<0.05 compared with TNF-a alone. 
in HCT-116 and HT-29 cells (Fig. 2A and B). IL-8 mRNA levels were significantly down-regulated by astragalin pretreatment in both HCT-116 and HT-29 cells (Fig. 2C and D). The mRNA expression of TNF- $\alpha$ is also reduced by the treatment of astragalin (Fig. 2E and F).

\section{Astragalin suppressed IKBa phosphorylation in TNF- $\alpha$-stimulated HCT-116 and HT-29 cells}

The levels of phosphorylated and non-phosphorylated forms of $I_{\kappa} B \alpha$ were estimated by Western blot analysis. When stimulated by TNF- $\alpha$, the phosphorylated $\mathrm{I}_{\kappa} \mathrm{B} \alpha$ markedly increased and $\mathrm{I}_{\kappa} \mathrm{B} \alpha$ decreased in HCT-116 and HT-29 cells. However, the pretreatment with astragalin suppressed the phosphorylation and degradation of $I_{\kappa} B \alpha$ in dose-dependent manner (Fig. 3).

\section{Astragalin reduces DNA binding activity of NF-KB in HCT-116 cells}

EMSA was performed to detect the changes in the DNA binding activity of NF- $\kappa \mathrm{B}$. Strong DNA binding activity was observed in the nuclear extract of HCT-116 cells after TNF- $\alpha$ stimulation, however, this activity was markedly prohibited after astragalin pretreatment (Fig. 4).

\section{Astragalin attenuates experimental colitis in DSS- induced acute murine colitis model}

The mice in the vehicle group showed the most severe body weight loss, whereas the control group showed higher body weight compared with vehicle group. Astragalin showed tendency of reduced body weight loss, albeit statistically insignificant (Fig. 5A). Mice in the vehicle group showed shortened colon length, whereas the oral treatment with astragalin improved colon shortening (Fig. 5B). On histologic exam, oral administration of astragalin induced a significant improvement of colonic inflammation compared with vehicle groups (Fig. 5C and E).

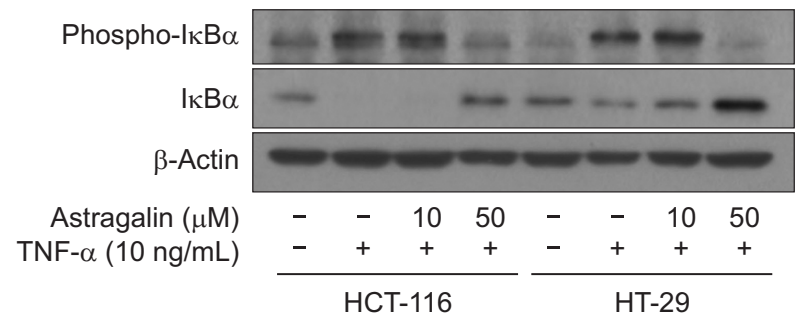

Fig. 3. Effect of astragalin on inhibitor of nuclear factor $k B$-alpha ( $/ k B a)$ phosphorylation/degradation in colonic epithelial cells. HCT-116 and HT-29 cells were treated with astragalin at different concentrations $(0,10$, and $50 \mu \mathrm{M})$ and stimulated with $10 \mathrm{ng} / \mathrm{mL}$ tumor necrosis factor a (TNF-a) for 30 minutes. Whole-cell extracts were prepared and analyzed for $\mathrm{lkBa}$ and phospho-I $\mathrm{kBa}$ expression.

\section{Astragalin attenuated the amount of phosphory- lated IKBa in DSS-induced acute murine colitis model}

In vehicle group, cells in destroyed epithelium and lamina propria of colon tissues showed strong staining of phosphorylated $I_{\kappa} B \alpha$. Oral administration of astragalin ameliorated IкB $\alpha$ phosphorylation in colon tissue (Fig. 5D and F).

\section{Astragalin inhibits the production of inflammatory cytokines in DSS-induced acute murine colitis model}

To investigate anti-inflammatory effect of astragalin in DSS-induced acute murine colitis model, mRNA expressions for IL-6, IL- 8 and TNF- $\alpha$ were analyzed using RTPCR. After treatment with astragalin, mRNA expression of IL-6, IL- 8 and TNF- $\alpha$ in mice colonic extracts were markedly reduced dose-dependently (Fig. 6).

\section{DISCUSSION}

In the present study, we proved that astragalin shows anti-inflammatory effect through the NF-кB pathway inhibition and attenuated murine colitis. When treated with astragalin, the phosphorylation of $\mathrm{I}_{\kappa} \mathrm{B} \alpha$ decreased and degradation of $\mathrm{I}_{\kappa} \mathrm{B} \alpha$ also lowered. Astragalin reduced DNA binding activity of NF- $\mathrm{KB}$, and as a result, the expression of inflammatory cytokines decreased. We aimed to demonstrate anti-inflammatory effect of astragalin in colonic

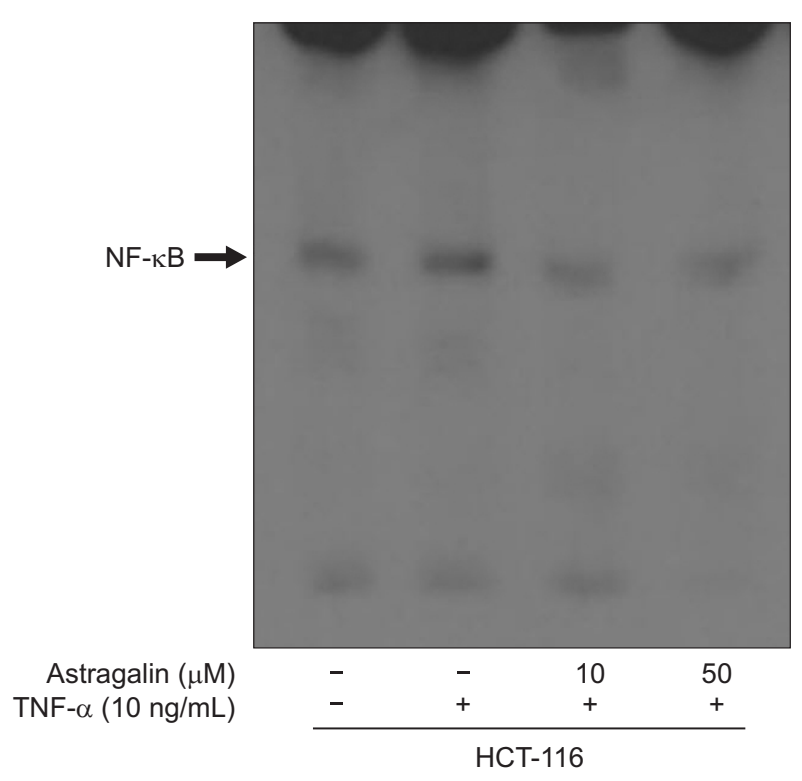

Fig. 4. Effect of astragalin on the DNA binding activity of nuclear factor $\mathrm{KB}(\mathrm{NF}-\mathrm{KB})$ in colonic epithelial cells. HCT-116 cells were treated with astragalin at different concentrations $(0,10$, and $50 \mu \mathrm{M})$ and stimulated with $10 \mathrm{ng} / \mathrm{mL}$ tumor necrosis factor a (TNF-a) for 30 minutes. The DNA binding activity was evaluated using electrophoretic mobility shift assay. 

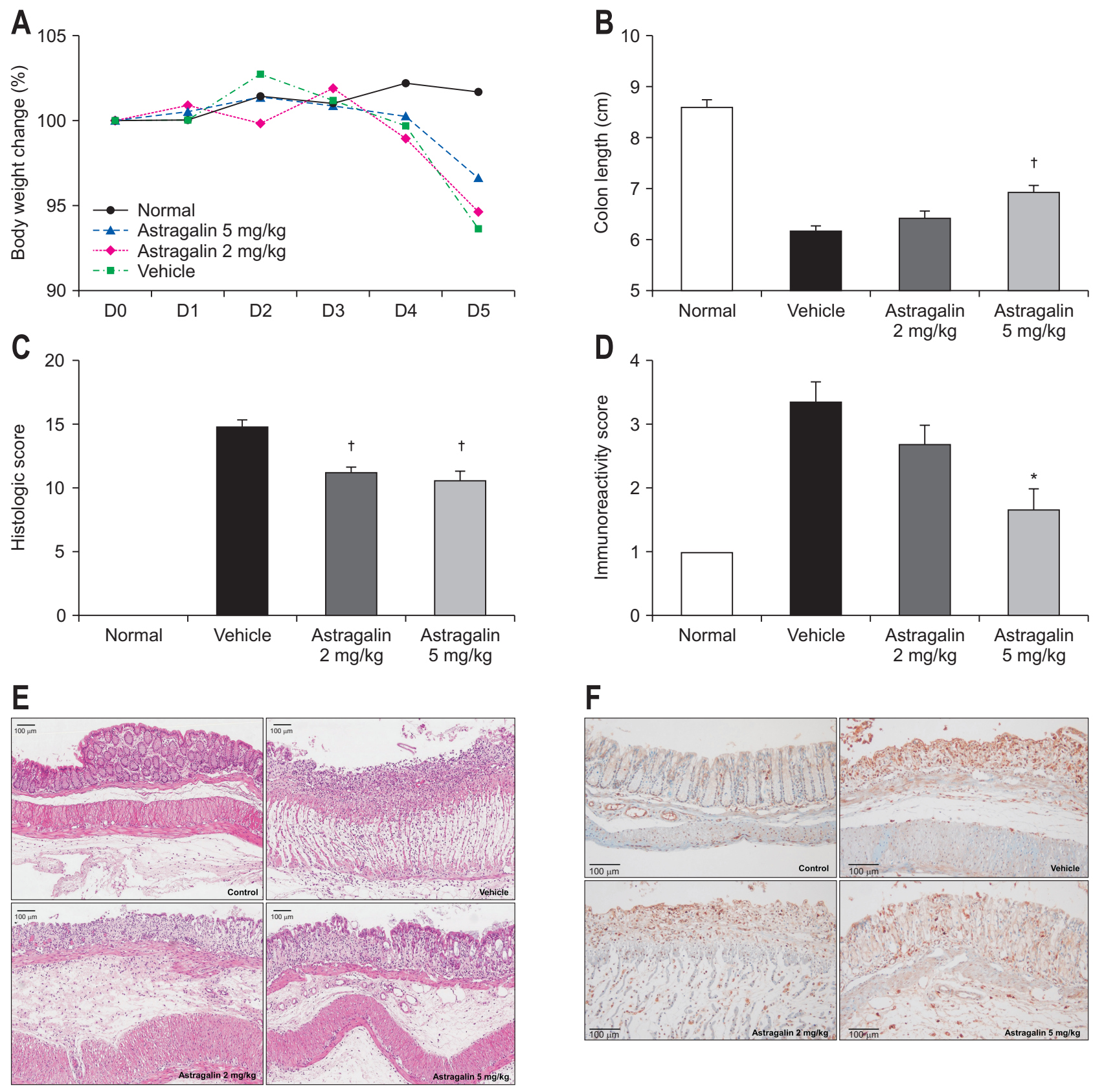

Fig. 5. Effect of astragalin on dextran sulfate sodium (DSS)-induced acute murine colitis. (A) Oral administration of astragalin significantly reduced the degree of body weight loss compared with that of vehicle-treated mice. (B) Colon shortening improved with oral administration of astragalin. (C) Treatment with astragalin significantly improved the histologic scores of mice with colitis compared with those of vehicle-treated mice. (D) Astragalin reduced colitis-induced inhibitor of nuclear factor $\mathrm{kB}$-alpha ( $\mathrm{kBB}$ ) phosphorylation in the colonic mucosa. (E) Oral administration of astragalin attenuated the destruction of crypts, damage to the epithelium and infiltration of inflammatory cells (H\&E). (F) Oral administration of astragalin reduced the level of phosphorylated IKBa in both destroyed epithelial cells and inflammatory cells (immunohistochemical staining). ${ }^{*} p<0.05$ and ${ }^{+} p<0.01$ compared with vehicle.

epithelial cell, because anti-inflammatory effect induced by $\mathrm{NF}-\kappa \mathrm{B}$ down regulation could be different depending on the cell types. The novel finding is that our study demonstrated the anti-inflammatory effects of astragalin on human colonic epithelial cell for the first time. Furthermore, we showed that astragalin ameliorates experimental colitis by down regulation $\mathrm{NF}-\kappa \mathrm{B}$ pathway.

NF- $\kappa B$ pathway activation promoted the production of many proinflammatory cytokines and triggered a proinflammatory cascade. NF- $\kappa \mathrm{B}$ pathway is a key pathway of IBD. NF- $\kappa \mathrm{B}$ is bound by $\mathrm{I}_{\kappa} \mathrm{B} \alpha$, which is an inhibitory molecule. When inflammatory cascade was triggered, phos- 

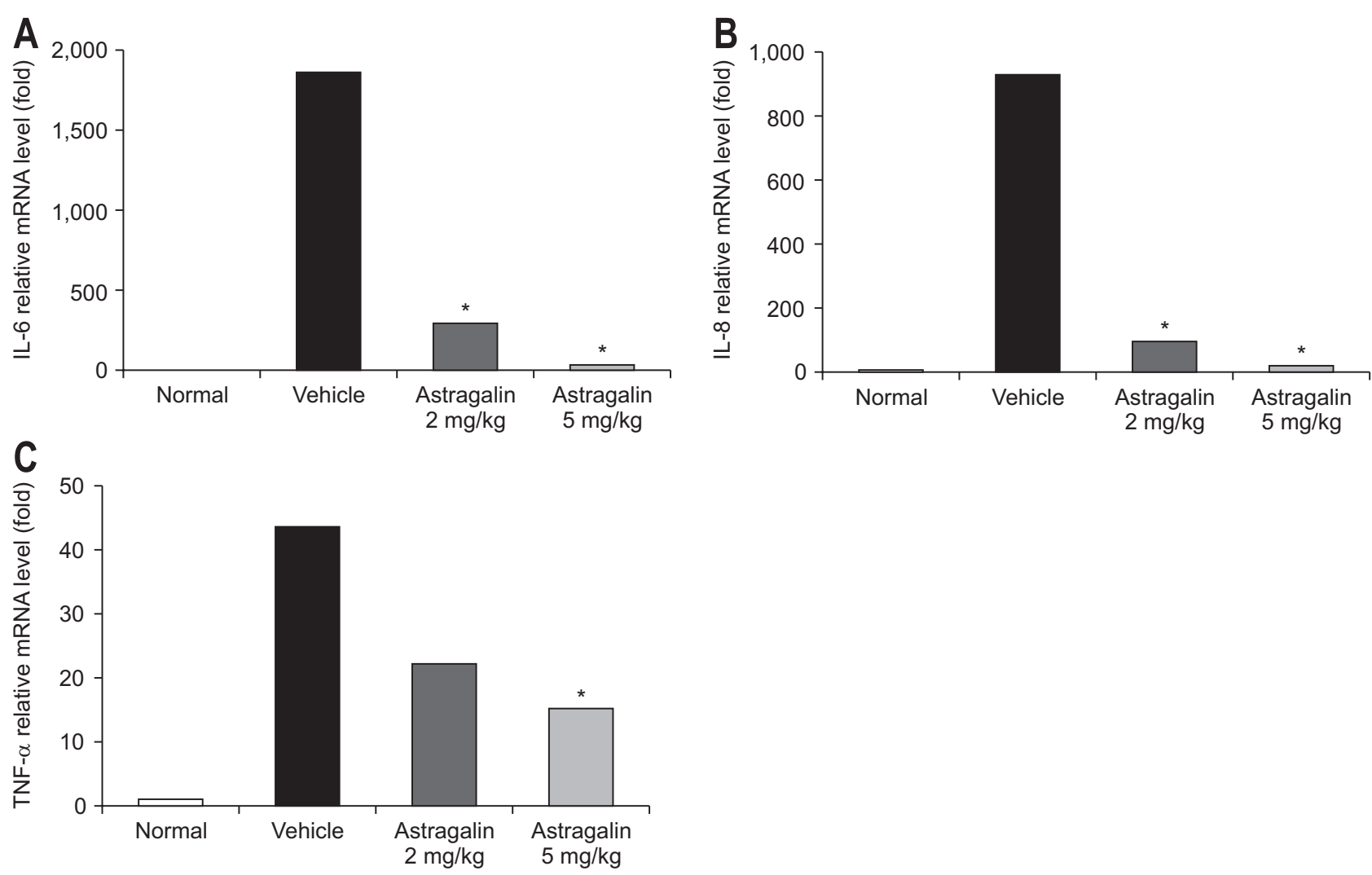

Fig. 6. Effect of astragalin on the messenger RNA (mRNA) expression of inflammatory cytokines in dextran sulfate sodium (DSS)-induced acute murine colitis. Oral administration of astragalin significantly and dose-dependently reduced mRNA expression of (A) IL-6, (B) IL-8, and (C) TNF-a in murine colonic extracts.

IL, interleukin; TNF, tumor necrosis factor. ${ }^{*} p<0.05$ compared with vehicle.

phorylation of $I_{\kappa} B \alpha$ increased, resulting in the increased degradation of $I_{\kappa} B \alpha$. This promotes NF- $\kappa B$ being free to bind DNA, thus, DNA binding activity of NF- $\kappa \mathrm{B}$ is enhanced in both intestinal epithelial cells and macrophages. Finally, the NF- $\kappa$ B-induced inflammatory cytokine production promoted. Many established therapeutic agents, such as corticosteroids, 5 -aminosalycilic acid, methotrexate, and anti-TNF- $\alpha$ agents, exerted its effect through the inhibition of NF- $\mathrm{KB}$ pathway. ${ }^{17-20}$

Astragalin has been investigated as an anti-inflammatory drug due to suppression of inflammatory cascade in various cell lines, although the exact mechanisms of astragalin are lacking. In recent, potential relation between astragalin and NF- $\kappa \mathrm{B}$ pathway has been revealed. Astragalin efficiently inhibited inflammatory mediator such as TNF- $\alpha$, IL-1 $\beta$, and IL- 6 and macrophage derived chemokine such as macrophage inflammatory protein- $1 \alpha$, monocyte chemotactic protein-1 in macrophages. ${ }^{8}$ Astragalin showed its anti-inflammatory activity by protecting mice from lethal sepsis and defending mice against acute lung injury induced by LPS. ${ }^{11}$ In vivo studies using LPS-induced mastitis murine model also reported that astragalin attenuated inflammatory cell infiltration and expression of inflammatory mediators. ${ }^{21,22}$ Another study proved that astragalin suppressed NF- $\kappa$ B on IL-1 $\beta$-induced inflammation in chondrocytes. ${ }^{23}$ Several previous studies which showed anti-inflammatory effect of astragalin raised expectation for the possibility of anti-colitis effect of astragalin. Herein, we aimed to prove the anti-inflammatory effect of astragalin in colonic epithelial cell and experimental colitis model, thus, to see the potential therapeutic effect for IBD through the modulation of inflammatory process. We proved that astragalin act as a potent inhibitor of NF- $\mathrm{KB}$ pathway in colonic epithelial cell. We also proved that astragalin showed anti-colitic effect in murine colitis model. Considering these findings, astragalin showed a possibility of a therapeutic option for IBD.

To apply these results from bench to clinics, further supporting studies are warranted. First, anti-inflammatory effect of astragalin could be further validated in vivo therapeutic models. We used DSS-induced acute murine colitis model $^{7,16}$ and proved that astragalin was effective in preventing acute colitis. Additional experiment using chronic colitis model of IL-10 -/- mice would be appropriate to 
prove therapeutic effect of astragalin in vivo. IL-10 -/mice revealed marked chronic colonic inflammation by the administration of nonsteroidal anti-inflammatory drug and widely used to discover the potential treatment effects of new drugs on chronic colitis. ${ }^{24}$ Second issue is a safety problem. Astragalin is a natural flavonoid that widely found in fruit and vegetables, and until now, no specific adverse effect or toxicity was reported. However, further experiments are mandatory to evaluate the safety according to the dose and duration, because there are remaining concern about potential harmful effect. Although multiple therapeutic administrations of astragalin in variable diseased status have been reported, further investigations are still needed to ultimately lead towards potent drug candidates, for example, structural optimization to upgrade its absorption profiles, improve its chemical accessibility, and to synthesize more effective analogues. ${ }^{25}$

In conclusion, astragalin showed anti-inflammatory effect through the inhibition of NF- $\kappa \mathrm{B}$ pathway and attenuated murine colitis. Astragalin might be potential therapeutic agent for IBD.

\section{CONFLICTS OF INTEREST}

No potential conflict of interest relevant to this article was reported.

\section{ACKNOWLEDGEMENTS}

This work was supported by grant number 04-20170230 from the Seoul National University Hospital (SNUH) Research Fund.

The authors appreciate Kah Young Lee, Jinwon Kwon, and Mi Ri Hyun (Seoul National University Hospital, Seoul, Korea) for their excellent technical assistance.

\section{AUTHOR CONTRIBUTIONS}

Conceptualization: Y.M.H., J.P.I., J.S.K. Methodology: Y.M.H., J.K., J.H.K., J.L. Formal analysis: Y.M.H., J.K., J.H.K., J.L. Funding acquisition: J.S.K. Project administration: J.S.K. Visualization: Y.M.H., J.K. Writing - original draft: Y.M.H. Writing - review and editing: Y.M.H., J.K., J.P.I., J.S.K. Approval of final manuscript: all authors.
ORCID

Yoo Min Han https://orcid.org/0000-0001-5580-8427 Jaemoon Koh https://orcid.org/0000-0002-2824-5080 Jee Hyun Kim https://orcid.org/0000-0003-1019-6345 Jooyoung Lee https://orcid.org/0000-0003-1652-088X Jong Pil Im https://orcid.org/0000-0003-1584-0160 Joo Sung Kim https://orcid.org/0000-0001-6835-4735

\section{REFERENCES}

1. Lee S, Ye BD. Are there interregional differences in the epidemiology and clinical characteristics of Crohn's disease in the Asia-Pacific region? Intest Res 2016;14:2-4.

2. Nagao-Kitamoto H, Kitamoto S, Kuffa P, Kamada N. Pathogenic role of the gut microbiota in gastrointestinal diseases. Intest Res 2016;14:127-138.

3. Ng WK, Wong SH, Ng SC. Changing epidemiological trends of inflammatory bowel disease in Asia. Intest Res 2016;14:111-119.

4. Shawki S, Ashburn J, Signs SA, Huang E. Colon cancer: inflammation-associated cancer. Surg Oncol Clin N Am 2018;27:269-287.

5. Grivennikov SI, Karin M. Dangerous liaisons: STAT3 and NF-kappaB collaboration and crosstalk in cancer. Cytokine Growth Factor Rev 2010;21:11-19.

6. Grivennikov S, Karin E, Terzic J, et al. IL-6 and Stat3 are required for survival of intestinal epithelial cells and development of colitis-associated cancer. Cancer Cell 2009;15:103113.

7. Neurath MF, Pettersson S, Meyer zum Büschenfelde KH, Strober W. Local administration of antisense phosphorothioate oligonucleotides to the p65 subunit of NF-kappa B abrogates established experimental colitis in mice. Nat Med 1996;2:998-1004.

8. Kim MS, Kim SH. Inhibitory effect of astragalin on expression of lipopolysaccharide-induced inflammatory mediators through NF- $\kappa \mathrm{B}$ in macrophages. Arch Pharm Res 2011;34:2101-2107.

9. Lee HB, Kim EK, Park SJ, Bang SG, Kim TG, Chung DW. Isolation and anti-inflammatory effect of astragalin synthesized by enzymatic hydrolysis of tea seed extract. J Sci Food Agric 2011;91:2315-2321.

10. Nhiem NX, Tai BH, Quang TH, et al. A new ursane-type triterpenoid glycoside from Centella asiatica leaves modulates the production of nitric oxide and secretion of TNF- $\alpha$ in activated RAW 264.7 cells. Bioorg Med Chem Lett 2011;21:1777-1781.

11. Soromou LW, Chen N, Jiang L, et al. Astragalin attenuates lipopolysaccharide-induced inflammatory responses by 
down-regulating NF- $\kappa \mathrm{B}$ signaling pathway. Biochem Biophys Res Commun 2012;419:256-261.

12. Seo JY, Lee C, Hwang SW, Chun J, Im JP, Kim JS. Nimbolide inhibits nuclear factor- $\kappa \mathrm{B}$ pathway in intestinal epithelial cells and macrophages and alleviates experimental colitis in mice. Phytother Res 2016;30:1605-1614.

13. Hwang SW, Kim JH, Lee C, Im JP, Kim JS. Intestinal alkaline phosphatase ameliorates experimental colitis via toll-like receptor 4-dependent pathway. Eur J Pharmacol 2018;820:156166.

14. Lee C, Lee JW, Seo JY, Hwang SW, Im JP, Kim JS. Lupeol inhibits LPS-induced NF-kappa B signaling in intestinal epithelial cells and macrophages, and attenuates acute and chronic murine colitis. Life Sci 2016;146:100-108.

15. Lee C, Kim BG, Kim JH, Chun J, Im JP, Kim JS. Sodium butyrate inhibits the NF-kappa B signaling pathway and histone deacetylation, and attenuates experimental colitis in an IL-10 independent manner. Int Immunopharmacol 2017;51:47-56

16. Dieleman LA, Palmen MJ, Akol H, et al. Chronic experimental colitis induced by dextran sulphate sodium (DSS) is characterized by Th1 and Th2 cytokines. Clin Exp Immunol 1998;114:385-391.

17. Auphan N, DiDonato JA, Rosette C, Helmberg A, Karin M. Immunosuppression by glucocorticoids: inhibition of NFkappa B activity through induction of I kappa B synthesis. Science 1995;270:286-290.

18. Guidi L, Costanzo M, Ciarniello M, et al. Increased levels of NF-kappaB inhibitors (IkappaBalpha and IkappaBgamma) in the intestinal mucosa of Crohn's disease patients dur- ing infliximab treatment. Int J Immunopathol Pharmacol 2005;18:155-164.

19. Majumdar S, Aggarwal BB. Methotrexate suppresses NFkappaB activation through inhibition of IkappaBalpha phosphorylation and degradation. J Immunol 2001;167:29112920.

20. Weber CK, Liptay S, Wirth T, Adler G, Schmid RM. Suppression of NF-kappaB activity by sulfasalazine is mediated by direct inhibition of IkappaB kinases alpha and beta. Gastroenterology 2000;119:1209-1218.

21. Li F, Wang W, Cao Y, et al. Inhibitory effects of astragalin on lipopolysaccharide-induced inflammatory response in mouse mammary epithelial cells. J Surg Res 2014;192:573581.

22. Li F, Liang D, Yang Z, et al. Astragalin suppresses inflammatory responses via down-regulation of NF- $\mathrm{BB}$ signaling pathway in lipopolysaccharide-induced mastitis in a murine model. Int Immunopharmacol 2013;17:478-482.

23. Ma Z, Piao T, Wang Y, Liu J. Astragalin inhibits IL-1 $\beta$ induced inflammatory mediators production in human osteoarthritis chondrocyte by inhibiting NF- $\mathrm{BB}$ and MAPK activation. Int Immunopharmacol 2015;25:83-87.

24. Kang SJ, Kim JM, Koh SJ, et al. The guggulsterone derivative GG-52 inhibits NF- $\kappa \mathrm{B}$ signaling in bone marrow-derived dendritic cells and attenuates colitis in IL-10 knockout mice. Life Sci 2013;92:1064-1071.

25. Riaz A, Rasul A, Hussain G, et al. Astragalin: a bioactive phytochemical with potential therapeutic activities. Adv Pharmacol Sci 2018;2018:9794625. 